Louisiana State University

LSU Digital Commons

Faculty Publications

Department of Chemistry

$9-15-2011$

\title{
Highly efficient extraction of phenolic compounds by use of magnetic room temperature ionic liquids for environmental remediation
}

\author{
Ning Deng \\ Hefei University of Technology \\ Min Li \\ Louisiana State University \\ Lijie Zhao \\ Louisiana State University \\ Chengfei Lu \\ Louisiana State University \\ Sergio L. de Rooy \\ Louisiana State University
}

See next page for additional authors

Follow this and additional works at: https://digitalcommons.Isu.edu/chemistry_pubs

\section{Recommended Citation}

Deng, N., Li, M., Zhao, L., Lu, C., de Rooy, S., \& Warner, I. (2011). Highly efficient extraction of phenolic compounds by use of magnetic room temperature ionic liquids for environmental remediation. Journal of Hazardous Materials, 192 (3), 1350-1357. https://doi.org/10.1016/j.jhazmat.2011.06.053

This Article is brought to you for free and open access by the Department of Chemistry at LSU Digital Commons. It has been accepted for inclusion in Faculty Publications by an authorized administrator of LSU Digital Commons.

For more information, please contact ir@lsu.edu. 
Authors

Ning Deng, Min Li, Lijie Zhao, Chengfei Lu, Sergio L. de Rooy, and Isiah M. Warner

This article is available at LSU Digital Commons: https://digitalcommons.Isu.edu/chemistry_pubs/2559 


\title{
Highly Efficient Extraction of Phenolic Compounds by Use of Magnetic Room Temperature Ionic Liquids for Environmental Remediation
}

\author{
Ning Deng ${ }^{2}$, Min Li ${ }^{1}$, Lijie Zhao ${ }^{1}$, Chengfei Lu ${ }^{1}$, Sergio L. de Rooy ${ }^{1}$, and Isiah M. Warner ${ }^{1}$, \\ 1'Department of Chemistry, Louisiana State University, Baton Rouge, LA70803, USA \\ ${ }^{2}$ School of Chemical Engineering, Hefei University of Technology, Hefei, Anhui Province, 230009, \\ China
}

\section{Abstract}

A hydrophobic magnetic room temperature ionic liquid (MRTIL), trihexyltetradecylphosphonium tetrachloroferrate(III) $\left(\left[3 \mathrm{C}_{6} \mathrm{PC}_{14}\right]\left[\mathrm{FeCl}_{4}\right]\right)$, was synthesized from trihexyltetradecylphosphonium chloride and $\mathrm{FeCl}_{3} \cdot 6 \mathrm{H}_{2} \mathrm{O}$. This MRTIL was investigated as a possible separation agent for solvent extraction of phenolic compounds from aqueous solution. Due to its strong paramagnetism, $\left[3 \mathrm{C}_{6} \mathrm{PC}_{14}\right]\left[\mathrm{FeCl}_{4}\right]$ responds to an external neodymium magnet, which was employed in the design of a novel magnetic extraction technique. The conditions for extraction, including extraction time, volume ratio between MRTIL and aqueous phase, $\mathrm{pH}$ of aqueous solution, and structures of phenolic compounds were investigated and optimized. The magnetic extraction of phenols achieved equilibrium in $20 \mathrm{~min}$ and the phenolic compounds were found to have higher distribution ratios under acidic conditions. In addition, it was observed that phenols containing a greater number of chlorine or nitro substitutents exhibited higher distribution ratios. For example, the distribution ratio of phenol $\left(\mathrm{D}_{\mathrm{Ph}}\right)$ was 107. In contrast, 3,5-dichlorophenol distribution ratio $\left(\mathrm{D}_{3,5-\mathrm{DCP}}\right)$ had a much higher value of 6372 under identical extraction conditions. When compared with four selected traditional non-magnetic room temperature ionic liquids, our $\left[3 \mathrm{C}_{6} \mathrm{PC}_{14}\right]\left[\mathrm{FeCl}_{4}\right]$ exhibited significantly higher extraction efficiency under the same experimental conditions used in this work. Pentachlorophenol, a major component in the contaminated soil sample obtained from a superfund site, was successfully extracted and removed by use of $\left[3 \mathrm{C}_{6} \mathrm{PC}_{14}\right]\left[\mathrm{FeCl}_{4}\right]$ with high extraction efficiency. Pentachlorophenol concentration was dramatically reduced from 7.8 $\mu \mathrm{g} . \mathrm{mL}^{-1}$ to $0.2 \mu \mathrm{g} \cdot \mathrm{mL}^{-1}$ after the magnetic extraction by use of $\left[3 \mathrm{C}_{6} \mathrm{PC}_{14}\right]\left[\mathrm{FeCl}_{4}\right]$.

\section{Keywords}

Ionic liquids; Phenols; Extraction; Magnetic; Superfund site

\section{Introduction}

Phenols are pollutants of major concern as a result of their widespread use, high toxicity and possible accumulation in the environment [1,2]. These compounds are present in wastewater

() 2011 Elsevier B.V. All rights reserved.

*Corresponding author, Isiah M. Warner: iwarner@1su.edu, Tel: 1-225-578-2829, Fax: 1-225-578-3971.

Publisher's Disclaimer: This is a PDF file of an unedited manuscript that has been accepted for publication. As a service to our customers we are providing this early version of the manuscript. The manuscript will undergo copyediting, typesetting, and review of the resulting proof before it is published in its final citable form. Please note that during the production process errors may be discovered which could affect the content, and all legal disclaimers that apply to the journal pertain. 
of a great variety of industries, such as refineries, coking operations, coal processing, petrochemical manufacturing, coal gasification liquefaction processes, pharmaceutical plastics, wood products, paint, and pulp and paper industries $[3,4]$. Therefore, phenolic compounds should be removed before the water can be recycled or discharged into the environment [5]. Phenols can be degraded to harmless compounds by bacteria and fungi under aerobic or anaerobic conditions [6,7]. However, major disadvantages of biological degradation include the low survival of microorganisms under high phenol concentrations and extended exposure. In addition, thermal decomposition of phenols is limited to small scale wastewater treatment [8-11]. Adsorption is an effective method that can be used to treat dilute phenols in wastewater [12-15]. However, this method may not be useful for treating high concentrated phenolic wastewater due to the high cost of sorbents [16-19]. Other approaches for phenol removal including electrochemical conversion [20], membrane filtration [21], and supercritical fluid extraction [22] have also been reported.

Liquid-liquid extraction is an effective separation technique for use in analytical science and chemical industry. In general, traditional solvent extraction employs a partitioning of a solute between two immiscible phases, typically an organic solvent and an aqueous solution. The solvent extraction method has the advantage of treating high concentrated phenolic wastewater [16]. However, the organic solvents used in traditional solvent extraction systems are usually volatile, toxic and flammable. Therefore, it is desirable and worthwhile to explore more effective and cleaner alternative extraction solvents for the development of new separation processes.

Room temperature ionic liquids (RTILs) are salts with a melting point close to or below room temperature. RTILs have recently been claimed as "green" solvents mainly due to their extremely low vapor pressure. In contrast to conventional volatile organic extraction solvents, RTILs are nonflammable, chemically and thermally stable, and have no detectable vapor pressure [23]. Therefore, as new alternative extraction solvents, RTILs have been successfully used to extract and separate various compounds from organic or aqueous solutions [24-30]. However, it is worth noting that RTILs used to date are non-magnetic and predominantly based on imidazolium and phosphonium salts. Recently, the development of magnetic room temperature ionic liquids (MRTILs) was reported [31,32]. These MRTILs are primarily based on high-spin $\mathrm{d}^{5}$ iron(III) in the form of tetrachloro- or tetrabromoferrate(III) with various counter cations. Owing to the high single-ion magnetic moment, these MRTILs exhibit a strong response to external magnetic fields. Other MRTILs containing different transition metal ions such as gadolinium and dysprosium have also been reported $[33,34]$. However, to date there have not been any reports of these MRTILs as novel extraction solvents. In our view, the use of MRTILs as extraction solvents may provide a new separation technique which can capitalize on the magnetic property of MRTILs. A number of advantages should accrue from use of this novel magnetic solvent extraction approach. For example, the use of an external magnetic field to remove the extraction solvent and realize the phase contact and separation would be interesting for theoretical studies since this concept has not been previously explored. Such a study would yield useful information and knowledge about the novel magnetic separation process. In addition, magnetic extraction may overcome the formation of undesirable emulsification. The formation of emulsions, which frequently occurs in traditional extraction processes, has been reported to produce obstacles and inconveniences during phase separation and recovery of the extraction solvent. Herein, we report on the application of an MRTIL as an extraction solvent for the separation of various phenolic compounds from aqueous solution. Experimental measurements are performed to determine the distribution ratios of the phenols and thus to optimize this novel magnetic extraction process. 


\section{Experimental}

\subsection{Chemicals and materials}

Trihexyltetradecylphosphonium chloride (95\%), $\mathrm{FeCl}_{3} \cdot 6 \mathrm{H}_{2} \mathrm{O}(\geq 99.9 \%), \mathrm{NaBF}_{4}(98 \%)$, $\mathrm{KPF}_{6}(98 \%)$, lithium bis(trifluoromethanesulfonyl)imide $\left(\operatorname{LiTf}_{2} \mathrm{~N}\right)(\geq 99 \%)$, phenol $(\mathrm{Ph})$ (99\%), 4-nitrophenol (4-NP) ( $\geq 99 \%)$, 2-chlorophenol (2-CP) ( $\geq 99 \%)$, 4-chlorophenol (4CP) ( $\geq 99 \%)$, 2,3-dichlorophenol (2,3-DCP) (98\%), 2,4-dichlorophenol (2,4-DCP) (99\%), 3,5-dichlorophenol (3,5-DCP) (97\%), 3,4-dichlorophenol (3,4-DCP) (99\%), pentachlorophenol (penta-CP) (98\%), 2-benzyl-4-chlorophenol (2-Ben-4-CP) (95\%), and 1butyl-2,3-dimethylimidazolium hexafluorophosphate $\left(\left[\mathrm{BM}_{2} \mathrm{IM}\right]\left[\mathrm{PF}_{6}\right]\right)(\geq 97 \%)$ were obtained from Sigma-Aldrich (Milwaukee, Wisconsin, USA) and used without further purification. Ethanol, methanol, and chloroform were of anhydrous grade (Sigma-Aldrich, Milwaukee, WI), and all other organic solvents such as acetonitrile and water were of HPLC grade (J. T. Baker, Phillipsburg, NJ). Contaminated soil samples acquired from a superfund site were kindly donated by Professor Barry Dillinger in the Department of Chemistry at Louisiana State University.

By use of anion-exchange reactions, regular non-magnetic RTILs, trihexyltetradecylphosphonium bis(trifluoromethanesulfonyl)imide $\left(\left[3 \mathrm{C}_{6} \mathrm{PC}_{14}\right]\left[\mathrm{Tf}_{2} \mathrm{~N}\right]\right)$, trihexyltetradecylphosphonium tetrafluoroborate $\left(\left[3 \mathrm{C}_{6} \mathrm{PC}_{14}\right]\left[\mathrm{BF}_{4}\right]\right)$, and tetrahexylphosphonium bis(trifluoromethanesulfonyl)imide $\left(\left[4 \mathrm{C}_{6} \mathrm{P}\right]\left[\mathrm{Tf}_{2} \mathrm{~N}\right]\right)$ were synthesized according to the procedure previously reported [35,36]. The $\mathrm{pH}$ values of the aqueous solutions were adjusted by use of aqueous solutions of $\mathrm{HCl}$ or $\mathrm{NaOH}$ and were measured by use of a digital $\mathrm{pH}$ meter.

\subsection{Synthesis of MRTIL $\left[3 \mathrm{C}_{6} \mathrm{PC}_{14}\right]\left[\mathrm{FeCl}_{4}\right]$}

$\left[3 \mathrm{C}_{6} \mathrm{PC}_{14}\right]\left[\mathrm{FeCl}_{4}\right]$ was synthesized by use of a reaction between trihexyltetradecylphosphonium chloride $\left(\left[3 \mathrm{C}_{6} \mathrm{PC}_{14}\right][\mathrm{Cl}]\right)$ and iron(III) chloride hexahydrate $\left(\mathrm{FeCl}_{3} \cdot 6 \mathrm{H}_{2} \mathrm{O}\right)$ in anhydrous methanol at room temperature for $24 \mathrm{~h}$ (Scheme 1) [33]. A typical synthesis procedure is described as follows. To a solution of trihexyltetradecylphosphonium chloride in anhydrous methanol solution was added equal molar amount of iron(III) chloride hexahydrate, which was predissolved in anhydrous methanol. The resultant mixed yellow solution was stirred at room temperature for $24 \mathrm{~h}$ using a stirring rate of $400 \mathrm{rpm}$. After completion of the reaction, methanol was removed by rotavapor under vacuum. The resultant viscous brownish liquid was subsequently washed with a small amount of DI water. After careful removal of the upper water phase, the ionic liquid was further freezedried on a lyophilizer overnight. The final product, $\left[3 \mathrm{C}_{6} \mathrm{PC}_{14}\right]\left[\mathrm{FeCl}_{4}\right]$, is a dark brown viscous liquid. Anal. Calcd for $\mathrm{C}_{32} \mathrm{H}_{68} \mathrm{Cl}_{4} \mathrm{FeP}, \mathrm{C}, 56.40 ; \mathrm{H}, 10.06$. Found: $\mathrm{C}, 57.21 ; \mathrm{H}, 9.83$. The $\mathrm{pH}$ of this compound is estimated to be acidic as a result of hydrolysis of $\mathrm{FeCl}_{4}{ }^{-}$and its density is $1.02 \mathrm{mg} / \mathrm{ml}$.

\subsection{Characterization of [ $\left.3 \mathrm{C}_{6} \mathrm{PC}_{14}\right]\left[\mathrm{FeCl}_{4}\right]$ by UV-Vis, Thermal Gravimetric Analysis (TGA), Differential Scanning Calorimetry (DSC), Superconducting Quantum Interference Device (SQUID) and Rheometer}

To characterize $\left[3 \mathrm{C}_{6} \mathrm{PC}_{14}\right]\left[\mathrm{FeCl}_{4}\right]$, its visible absorption spectrum was measured using a Shimadzu UV-3101PC UV-Vis-near-IR scanning spectrometer (Shimadzu, Columbia, MD). Absorption was collected using a $1.0 \mathrm{~cm}^{2}$ quartz cuvette at room temperature with blank subtraction [32].

A TA Q50 thermal gravimetric analyzer (TA Instruments, New Castle, DE) was used to analyze the thermal stability of $\left[3 \mathrm{C}_{6} \mathrm{PC}_{14}\right]\left[\mathrm{FeCl}_{4}\right]$ and its thermal decomposition behaviour [32]. The temperature was scanned from room temperature to $773 \mathrm{~K}$ under nitrogen flow (50 
$\mathrm{ml} / \mathrm{min}$ ) with a heating rate of $10 \mathrm{~K} \cdot \mathrm{min}^{-1}$. The onset degradation temperature and peak temperature were determined using the derivative TGA curves. Glass transition behavior or melting point of $\left[3 \mathrm{C}_{6} \mathrm{PC}_{14}\right]\left[\mathrm{FeCl}_{4}\right]$ was investigated using a $\mathrm{Q} 100$ differential scanning calorimeter (TA Instruments, New Castle, DE). The sample was placed in a sealed aluminium crucible and analysis was performed under a nitrogen flow $(50 \mathrm{ml} / \mathrm{min})$. The sample was cooled to $207 \mathrm{~K}$, kept isothermal for $3 \mathrm{~min}$, and then heated to $333 \mathrm{~K}$ at a rate of $10 \mathrm{~K} \cdot \mathrm{min}^{-1}$.

The magnetic magnetization and susceptibility of $\left[3 \mathrm{C}_{6} \mathrm{PC}_{14}\right]\left[\mathrm{FeCl}_{4}\right]$ were measured using approximately $80 \mathrm{mg}$ of the sample in a Quantum Design Superconducting Quantum Interference Device (SQUID) magnetometer (San Diego, CA, USA) for fields between -50 000 and 50000 Oe.

A Rheometric Scientific RFSII rheometer (Geometry: $25 \mathrm{~mm}$ cone and plate with a $25 \mathrm{~mm}$ diameter, 0.04 radians cone angle, $0.05 \mathrm{~mm}$ truncation) was used to measure the viscosity of $\left[3 \mathrm{C}_{6} \mathrm{PC}_{14}\right]\left[\mathrm{FeCl}_{4}\right]$ at room temperature. In the first measurement, the viscosity was measured at constant shear rates $\left(0.02,0.1,0.5,1.0,10,25,50\right.$ and $\left.100 \mathrm{~s}^{-1}\right)$. Each shear rate was held for 20 seconds and the measurement was averaged for a 2 second interval. In the second test, the shear rate was ramped from $0-100 \mathrm{~s}^{-1}$, over 300 second time intervals. In each test, samples were loaded and allowed to thermally equilibrate for 15 seconds prior to test initiation.

\subsection{Preparation of standard stock solution}

Each phenol, including phenol ( $\mathrm{Ph}$ ), 4-nitrophenol (4-NP), 2-chlorophenol (2-CP), 4chlorophenol (4-CP), 2,4-dichlorophenol (2,4-DCP), 3,5-dichlorophenol (3,5-DCP), pentachlorophenol (penta-CP), and 2-benzyl-4-chlorophenol (2-Bn-4-CP) (Fig. 1) was dissolved in methanol to obtain a standard stock solution with a concentration of 2 $\mathrm{mg} \cdot \mathrm{mL}^{-1}$. The stock solutions were stored at $277 \mathrm{~K}$. Mixed standard stock solutions containing various phenolic compounds were prepared similarly in methanol and stored at $277 \mathrm{~K}$. Working solutions were prepared daily by diluting the standard stock solutions with DI water.

\subsection{Magnetic extraction operation}

In a capped glass vial $(20 \mathrm{~mL}),\left[3 \mathrm{C}_{6} \mathrm{PC}_{14}\right]\left[\mathrm{FeCl}_{4}\right](50 \mu \mathrm{L})$ was suspended in an aqueous phenolic solution $(6 \mathrm{~mL})$ with predetermined concentration (Fig. 2). Due to its strong paramagnetism, [ $\left.3 \mathrm{C}_{6} \mathrm{PC}_{14}\right]\left[\mathrm{FeCl}_{4}\right]$ responds to and moves in the prescence of a neodemium magnet $(\mathrm{B}=1.4 \mathrm{~T})$. The magnet was moved circularly by use of an oribital shaker (S500, VWR, West Chester, PA, USA) and the suspended $\left[3 \mathrm{C}_{6} \mathrm{PC}_{14}\right]\left[\mathrm{FeCl}_{4}\right]$ could move synchronously with the magnet in the aqueous phenolic solution (Fig. 2). After performance of magnetic extraction for a given time period, the phenol concentrations in the aqueous solution were determined by use of HPLC-UV.

\subsection{HPLC analysis}

Separation and quantitative analyses of phenolic compounds in aqueous solution were performed on a Shimadzu HPLC system (Kyoto, Japan) consisting of an SCL-10A system controller, two LC-10AD pumps, a DGU-14A degasser, a SIL-10AD autosampler and an SPD-10AV UV-Vis detector $(\lambda=210 \mathrm{~nm})$. Separation of the analytes was performed at room temperature on a Phenomenex Luna C18 column, $100 \AA$ A pore size, $4 \mu \mathrm{m}$ particle size, $250 \times 4.6 \mathrm{~mm}$ i.d. column containing a guard column (Phenomenex, Torrance, CA, USA). The analytes were eluted isocratically at a flow rate of $0.4 \mathrm{~mL} / \mathrm{min}$ using an acetonitrile/ water mobile phase $(65 / 35, \mathrm{v} / \mathrm{v})$. The water was pre-adjusted to $\mathrm{pH} 3$ by use of phosphoric acid. The sample injection volume was $20 \mu \mathrm{L}$ and 2-Bn-4-CP was used as an internal 
standard for the quantification of other phenolic compounds. The concentrations of phenolic compounds in the ionic liquid phase were calculated by use of mass balance.

\subsection{Calculations}

Distribution ratios (D) of the phenolic compounds between $\left[3 \mathrm{C}_{6} \mathrm{PC}_{14}\right]\left[\mathrm{FeCl}_{4}\right]$ and aqueous solution were calculated using the following equation (1) and the extraction percentages (E) were calculated according to equation (2).

$$
\begin{gathered}
D=\frac{C_{\mathrm{IL}}}{C_{\mathrm{w}}}=\frac{\mathrm{C}_{\mathrm{w}}^{0}-\mathrm{C}_{\mathrm{w}}}{C_{\mathrm{w}}} \times \frac{\mathrm{V}_{\mathrm{w}}}{\mathrm{V}_{\mathrm{IL}}} \\
\mathrm{E}=\frac{\mathrm{m}_{\mathrm{IL}}}{\mathrm{m}}=\frac{\mathrm{C}_{\mathrm{IL}} \times V_{\mathrm{IL}}}{C_{\mathrm{W}}^{0} \times V_{\mathrm{w}}}=\frac{D}{D+\frac{V_{\mathrm{W}}}{V_{\mathrm{IL}}}}
\end{gathered}
$$

where $\mathrm{C}_{\mathrm{w}}{ }^{0}$ and $\mathrm{C}_{\mathrm{w}}$ are the initial and equilibrium concentrations of the solute (phenols) in aqueous phase, respectively $\left(\mathrm{mg} \cdot \mathrm{L}^{-1}\right)$, and $\mathrm{V}_{\mathrm{W}}$ and $\mathrm{V}_{\mathrm{IL}}$ denote the volumes of aqueous and IL phases, respectively $(\mathrm{mL})$. The concentrations in aqueous solution were measured in triplicate by use of HPLC and their average values were reported. The key to increase of the extraction efficiency is to enhance the distribution ratio. Studies of distribution ratio and extraction equilibrium may provide insightful understanding of this novel separation process and ultimately aid in optimizing separation efficiencies [30].

\section{Results and discussion}

\subsection{Characterization of $\left[3 \mathrm{C}_{6} \mathrm{PC}_{14}\right]\left[\mathrm{FeCl}_{4}\right]$}

The absorption spectrum of the MRTIL $\left[3 \mathrm{C}_{6} \mathrm{PC}_{14}\right]\left[\mathrm{FeCl}_{4}\right]$ was measured using a UV-VisNIR spectrometer (Fig. 3). Three major peaks at 531, 613, and $687 \mathrm{~nm}$ were observed. These peaks are well known to be characteristic of the tetrachloroferrate(III) anion. These very similar absorption behaviors and peak wavelengths were also observed previously for the reported magnetic ionic liquids such as 1-butyl-3-methylimidazolium tetrachloroferrate(III) [31].

The thermal properties of $\left[3 \mathrm{C}_{6} \mathrm{PC}_{14}\right]\left[\mathrm{FeCl}_{4}\right]$ including thermal stability and phase transition behavior were investigated by use of TGA and DSC. From the TGA curve (Fig. 4) it can be seen that $\left[3 \mathrm{C}_{6} \mathrm{PC}_{14}\right]\left[\mathrm{FeCl}_{4}\right]$ is thermally stable up to temperatures nearing $623 \mathrm{~K}$ under nitrogen atmosphere. In addition, a one-stage thermal decomposition process was observed for $\left[3 \mathrm{C}_{6} \mathrm{PC}_{14}\right]\left[\mathrm{FeCl}_{4}\right]$. The compound $\left[3 \mathrm{C}_{6} \mathrm{PC}_{14}\right]\left[\mathrm{FeCl}_{4}\right]$ exhibits high storage stability under ambient conditions. As a matter of fact, $\left[3 \mathrm{C}_{6} \mathrm{PC}_{14}\right]\left[\mathrm{FeCl}_{4}\right]$ can still be used for magnetic extraction after it has been stored over one year at room temperature. According to the DSC result (data not shown), a major endothermic peak at $285 \mathrm{~K}$ was observed, which could be assigned to the melting point of $\left[3 \mathrm{C}_{6} \mathrm{PC}_{14}\right]\left[\mathrm{FeCl}_{4}\right]$.

The MRTIL [ $\left.3 \mathrm{C}_{6} \mathrm{PC}_{14}\right]\left[\mathrm{FeCl}_{4}\right]$ contains tetrachloroferrate(III) anions with $3 \mathrm{~d}^{5}$ configuration and displays paramagnetic behavior at room temperature. Its magnetic susceptibility was measured using a Quantum Design superconducting quantum interference device (SQUID). The magnetization at $300 \mathrm{~K}$ was measured in the magnetic field range of -50000 to 50000 Oe. The magnetization showed an expected linear dependence on the applied magnetic field (Fig. 5). From the slope of the linear fits to the data, the molar magnetic susceptibility of 
$\left[3 \mathrm{C}_{6} \mathrm{PC}_{14}\right]\left[\mathrm{FeCl}_{4}\right]$ was obtained as $\chi_{\mathrm{M}}=0.0135 \mathrm{emu} \mathrm{mol}^{-1}$, which conformed well to the value expected for $\mathrm{Fe}$ (III) [31, 33].

Viscosity tests of $\left[3 \mathrm{C}_{6} \mathrm{PC}_{14}\right]\left[\mathrm{FeCl}_{4}\right]$ based on shear stress/shear rate ratio showed a linear relationship indicating that this magnetic ionic liquid behaves as a Newtonian fluid over this shear rate range. Linear regression of the results showed that the viscosity of $\left[3 \mathrm{C}_{6} \mathrm{PC}_{14}\right]$ $\left[\mathrm{FeCl}_{4}\right]$ obtained is $0.914 \mathrm{~Pa}$.s at room temperature.

\subsection{Effect of extraction time}

Extraction time is one of the most important factors in most extraction processes because mass transfer of analytes between the two immiscible phases needs to overcome phase barrier energy [30]. This transport process takes time to occur and to reach equilibrium [37]. Therefore, the effect of extraction time on the distribution ratios of the phenols was studied. Four different phenolic compounds were extracted by use of $\left[3 \mathrm{C}_{6} \mathrm{PC}_{14}\right]\left[\mathrm{FeCl}_{4}\right]$ for various durations of time. The distribution ratios of the four phenols displayed a similar trend, i.e. they increased in the beginning of the extraction process (Fig. 6). However, the distribution ratios reached a plateau after 20 min extraction. Further increase of extraction time to 60 min did not significantly affect the phenol distribution ratios. These results may suggest that the extraction of phenols reached equilibrium in $20 \mathrm{~min}$. In addition, phase contact time required for the extraction of phenols into $\left[3 \mathrm{C}_{6} \mathrm{PC}_{14}\right]\left[\mathrm{FeCl}_{4}\right]$ does not depend significantly on the molecular structures of phenols. Therefore, a phase contact duration of 20 min was employed as the optimum extraction time for all the phenols in the following investigations.

\subsection{Effect of phase volume ratio}

In order to determine the effect of phase volume ratio between the aqueous solution and $\left[3 \mathrm{C}_{6} \mathrm{PC}_{14}\right]\left[\mathrm{FeCl}_{4}\right]$ on phenol distribution ratios, additional magnetic extraction experiments were conducted using 2,4-DCP as a representative phenolic compound. In all these magnetic extractions, aqueous solution volumes were increased while keeping the $\left[3 \mathrm{C}_{6} \mathrm{PC}_{14}\right]\left[\mathrm{FeCl}_{4}\right]$ volume constant $(50 \mu \mathrm{L})$ at the same time. The results from these studies demonstrate that the distribution ratio of 2,4-DCP between $\left[3 \mathrm{C}_{6} \mathrm{PC}_{14}\right]\left[\mathrm{FeCl}_{4}\right]$ and aqueous solution exhibited no significant change when the volume ratio was increased from $40(2 \mathrm{~mL} / 0.05 \mathrm{~mL})$ to 120 $(6 \mathrm{~mL} / 0.05 \mathrm{~mL})$ (Fig. 7). However, 2,4-DCP distribution ratios dramatically dropped with further increase of phase volume ratios (aqueous solution volume). The decrease in distribution ratios could possibly be due to the much greater volumes of aqueous phase as compared to the ionic liquid phase used in this extraction, which may enhance the dissolution of the IL into the aqueous phase. Due to the extremely high extraction efficiency of the MRTIL, we used only a small volume of MRTIL in order to develop our magnetic extraction process, which lowers consumption of MRTIL and fully capitalizes on its high extraction capacity. Therefore, a phase ratio of $120(6 \mathrm{~mL} / 0.05 \mathrm{~mL})$ was selected as the optimal value to increase the extraction capacity to the maxim, while still maintaining high distribution ratios.

\subsection{Effect of $\mathrm{pH}$ of aqueous solution}

It is well known that the $\mathrm{pH}$ of a sample solution could significantly influence extraction efficiency particularly when acidic or basic solutes are extracted. The target phenols are weak acids with low ionization constants. For example, the pKa values of 4-NP, 2-CP, and 2,4-DCP are 7.15, 8.56, and 7.85, respectively. Therefore, the $\mathrm{pH}$ was varied from $\mathrm{pH} 4$ to 10 to investigate the effect on phenol distribution ratios (Fig. 8). Higher distribution ratios were achieved at acidic conditions for all three phenols investigated. In contrast, the distribution ratio of 2,4-DCP significantly decreased when it was extracted in basic solutions. This typical partition behavior of phenolic compounds has been previously observed when quaternary ammonium salt-based ionic liquids were used [26,38]. Under 
acidic conditions, the disassociation of phenols was suppressed and phenols exist predominantly as neutral species. This observed $\mathrm{pH}$ dependence of extraction efficiency clearly suggests that phenols are preferably partitioned into MRTIL as non-dissociated species. However, it should be noted that even at $\mathrm{pH} 10$, the extraction of 2-CP into $\left[3 \mathrm{C}_{6} \mathrm{PC}_{14}\right]\left[\mathrm{FeCl}_{4}\right]$ is still quite significant. It has been reported that in the case of extraction of hydrophobic phenols, the effect of $\mathrm{pH}$ on distribution ratios into imidazolium- and quaternary ammonium-based ionic liquids was small [30]. Pletney and coworkers also observed that when $\mathrm{pH}$ was higher than 10, 4-chlorophenol (4-CP) could still be significantly extracted into 1-butyl-3-methylimidazolium hexafluorophosphate [BMIM] $\left[\mathrm{PF}_{6}\right]$. They proposed that extraction of anionic phenolate may proceed through an alternative pathway, i.e. anion exchange [39]. Therefore, the two different trends mentioned above suggest that in addition to the extraction of phenol in molecular form, the extraction of anionic phenolate into $\left[3 \mathrm{C}_{6} \mathrm{PC}_{14}\right]\left[\mathrm{FeCl}_{4}\right]$ through an anion-exchange mechanism may also occur.

\subsection{Effect of structures of the phenolic compounds}

Five phenols with different chlorine or nitro substituents were tested as solutes for magnetic extraction. In acidic aqueous solutions, distribution ratios of the phenols increased in the order of $\mathrm{Ph}<4-\mathrm{CP}<2-\mathrm{NP}<2$-CP $<3,4-\mathrm{DCP}<2,4-\mathrm{DCP}<3,5$-DCP under the same experimental conditions (Fig. 9). Higher distribution ratios were observed for phenols containing more chlorine substituents. This trend may suggest that the increased distribution ratios of phenols with more chlorine substituents could be due to their greater hydrophobic interactions with $\left[3 \mathrm{C}_{6} \mathrm{PC}_{14}\right]\left[\mathrm{FeCl}_{4}\right]$. Botsaris and coworkers reported the extraction of chlorophenols containing different number of chlorine substituents by imidazolium-based RTILs such as [BMIM] $\left.\mathrm{PF}_{6}\right]$ [40]. They found that partitioning of chlorophenols between the ionic liquid and water phase was significantly increased when chlorophenols containing more chlorine substituents were extracted. This behavior was similar to the trend that 1 octanol/water partition coefficients of chlorophenols exhibited [40].

\subsection{Effect of the structures of ionic liquids}

Four traditional non-magnetic RTILs were also investigated as extraction solvents for comparison with the MRTIL. The distribution ratios of both 2-CP and 2,4-DCP were significantly higher in the MRTIL $\left[3 \mathrm{C}_{6} \mathrm{PC}_{14}\right]\left[\mathrm{FeCl}_{4}\right]$ than in the four non-magnetic RTILs (Fig. 10). Among the four non-magnetic RTILs, higher distribution ratios of phenols were obtained when the phosphonium-based hydrophobic ionic liquids with long alkyl chains such as $\left[3 \mathrm{C}_{6} \mathrm{PC}_{14}\right]\left[\mathrm{BF}_{4}\right]$ and $\left[3 \mathrm{C}_{6} \mathrm{PC}_{14}\right]\left[\mathrm{Tf}_{2} \mathrm{~N}\right]$ were used. In contrast, the imidazoliumbased RTIL $\left[\mathrm{BM}_{2} \mathrm{IM}\right]\left[\mathrm{PF}_{6}\right]$ with shorter alkyl chain showed the lowest extraction efficiency. Increased extraction efficiency by use of ionic liquids containing longer alkyl chain was previously observed in a study where an ionic liquid-based headspace single-drop microextraction with $\mathrm{GC}$ for sensitive detection of phenols was reported [41]. These results suggest that for a given phenolic solute, its distribution ratios increase with increasing alkyl chain length on the cations of the ionic liquids used as extractants under acidic conditions. The trend of increasing extraction efficiency with increasing linear alkyl chain length can be attributed to the increase in hydrophobicity of the cation. Hydrophobicity, along with hydrogen bonding of the cation, plays a major role in the selective extraction of phenols from aqueous solution under acidic conditions [26]. In addition, according to a quantum chemical based "conductor-like screening model for real solvents" (COSMO-RS), an increase of the alkyl chain enhances the volume size of the channels formed by the interaction of the phosphonium - based cations and anions. The incresed interaction thus facilitates the accommodation of the phenol molecules by ionic liquids [42]. 
When the same cation, trihexyltetradecylphosphonium, was used, $\mathrm{BF}_{4}{ }^{-}$-containing ionic liquid displayed higher extraction efficiency than $\mathrm{Tf}_{2} \mathrm{~N}^{-}$- containing IL (Fig. 10). It has been reported that distribution ratios of phenols generally were found to decrease with increase in total screening charge values of anions [42]. This trend indicates that anions with low screening charges have a higher affinity for phenol in aqueous solution. This trend is also consistent with the fact that the higher the screening charge, the lower will be the polarizability of the molecule and the smaller will be the possibility of hydrogen bonding with phenols. Another manuscript from the literature reports on the separation of 1-hexene from n-hexane by use of ionic liquids. In that study, the authors also found that suitable ionic liquids should have small molecular volumes, unbranched groups, and a sterical shielding effect around the anion charge center. Headspace-gas chromatography verified that the anion with sterical shielding around the anion charge center is favorable for increasing selectivity [43]. The anion $\mathrm{BF}_{4}$-has a smaller steric shielding effect around its charge center than the anion $\mathrm{Tf}_{2} \mathrm{~N}^{-}$. Therefore, higher extraction efficiency in the $\mathrm{BF}_{4}{ }^{-}$- containing IL was obtained compared with that in the $\mathrm{Tf}_{2} \mathrm{~N}^{-}$- containing IL.

\subsection{Extraction of pentachlorophenol from contaminated soil samples}

A Superfund site is a hazardous waste site which has been placed on the National Priorities List (NPL), a list of polluted sites requiring cleanup which is maintained by the United States Environmental Protective Agency (EPA). Chlorinated phenols are toxic chemicals frequently found in hazardous wastes at superfund sites. Upon heating or burning they can be converted into even more toxic polychlorinated dibenzo-p-dioxins and dibenzofurans (PCDD/F) by both gas-phase and metal catalyzed pathways [44]. Pentachlorophenol is a manufactured chemical which is restricted in use as a pesticide and is used industrially as a wood preservative for utility poles, railroad ties, and wharf pilings. Exposure to high levels of pentachlorophenol can cause increases in body temperature, adverse liver effects, and damages to the immune system [45]. This substance has been found in at least 313 of the 1,585 National Priorities List sites identified by the EPA. The EPA has set a limit for drinking water of 1 part of pentachlorophenol per billion parts of water (1 ppb).

The HPLC chromatogram of a contaminated soil sample obtained from a superfund site is shown in Fig. 11a. The peak at 18.10 min was identified as pentachlorophenol (penta-CP) by both spiking standard pentachlorophenol and by use of LC-MS. The original concentration of penta-CP was determined as $7.8 \mu \mathrm{g} \cdot \mathrm{mL}^{-1}$ by use of an internal standard method. After extraction by $\left[3 \mathrm{C}_{6} \mathrm{PC}_{14}\right]\left[\mathrm{FeCl}_{4}\right]$ using our novel magentic extraction technique, the concentration of penta-CP was dramatically reduced to $0.2 \mu \mathrm{g} \cdot \mathrm{mL}^{-1}$. An HPLC chromatogram of the same sample after extraction is shown in Fig. 11b. Thus, the penta-CP peak significantly decreased due to the extraction. The extraction or removal efficiency under this optimzied conditions is $97.4 \%$, which indicates that the majority of penta-CP was removed.

\section{Conclusions}

In summary, we have developed a novel magnetic extraction technique for removal of phenolic compounds using a magnetic room temperature ionic liquid as a highly efficient extraction solvent. The distribution ratios of phenols were significantly influenced by $\mathrm{pH}$ of the aqueous phase, nature of the ILs, and chemical structure of the phenols themselves. Moreover, our MRTIL exhibited much higher extraction capacity than traditional nonfunctionalized RTILs under the same conditions used in this work. It can be expected that these results are promising for the liquid-liquid extraction, separation, and preconcentration of phenols in analytical and separation science. In addition to the contaminated soil samples obtained from superfund sites, application of this new magnetic extraction technique to remove phenolic compounds from other real samples such as 
industrial river and lake water samples is currently in progress. At the same time, we are currently attempting the development of an efficient approach to recovery and recycling our MRTIL. For example, we have explored centrifugation for separation of the magnetic ionic liquids from bulk aqueous phenolic solution. Another possible approach is to use a strong magnet for forcing MRTIL to the bottom of the glassware. The bulk solution can then be decanted out. The recovered MRTIL will then be recycled and tested for the next extraction of phenolic compounds.

\section{Acknowledgments}

We are thankful to Dr. Barry Dellinger of the LSU Superfund Research Program for kind donation of superfund site soil samples. This work is supported in part by the National Science Foundation (CHE-0911118). N. Deng gratefully acknowledges support of the Natural Science Foundation of Anhui Province, China (No. 090411011).

\section{References}

1. Ku Y, Lee KC. Removal of phenols from aqueous solution by XAD-4 resin. J Hazard Mater. 2000; 80:59-68. [PubMed: 11080569]

2. Olejniczak J, Staniewski J, Szymanowski J. Extraction of phenols and phenyl acetates with diethyl carbonate. Anal Chim Acta. 2005; 535:251-257.

3. González-Muňoz MJ, Luque S, Álvarez JR, Coca J. Recovery of phenol from aqueous solutions using hollow fibre contactors. J Membr Sci. 2003; 213:181-193.

4. Li Z, Wu M, Jiao Z, Bao B, Lu S. Extraction of phenol from wastewater by N-octanoylpyrrolidine. J Hazard Mater. 2004; 114:111-114. [PubMed: 15511580]

5. Buscaa G, Berardinelli S, Resini C, Arrighi L. Technologies for the removal of phenol from fluid streams: A short review of recent developments. J Hazard Mater. 2008; 160:265-288. [PubMed: 18455866]

6. Broholm MM, Erik A. Biodegradation of phenols in a sandstone aquifer under aerobic conditions and mixed nitrate and iron reducing conditions. J Contamin Hydro. 2000; 44:239-273.

7. Lee SY, Kim BN, Han JH, Chang ST, Choi YW, kim YH, Min J. Treatment of phenol-contaminated soil by Corynebacterium glutamicum and toxicity removal evaluation. J Hazard Mater. 2010; 182:937-940. [PubMed: 20638173]

8. Fortuny A, Font J, Fabregat A. Wet air oxidation of phenol using active carbon as catalyst. Appl Catal B: Environ. 1998; 19:165-173.

9. Akyurtlu JF, Ahyurtlu A, Kovenklioglu S. Catalytic oxidation of phenol in aqueous solutions. Catal Today. 1998; 40:343-352.

10. Yu JL, Phillip ES. Phenol oxidation over $\mathrm{CuO} / \mathrm{Al}_{2} \mathrm{O}_{3}$ in supercritical water. Appl Catal B: Environ. 2000; 28:275-288.

11. Portela JR, Nebot E, Ossa EM. Kinetic comparison between subcritical and supercritical water oxidation of phenol. Chem Eng J. 2001; 81:287-299.

12. Banat FA, Al-Bailey B, Al-Asheh S, Hayajneh O. Adsorption of phenol by bentonite. Environ Pollut. 2000; 107:391-398. [PubMed: 15092985]

13. Hebatpuria VM, Hassan AH, Rho HS. Immobilization of phenol in cement-based solidified/ stabilized hazardous wastes using regenerated activated carbon: leaching studies. J Hazard Mater. 1999; 70:117-138. [PubMed: 10631352]

14. Rengaraj S, Moon SH, Sivabalan R, Arabindoo B, Murugesan V. Removal of phenol from aqueous solution and resin manufacturing industry wastewater using an agricultural waste: rubber seed coat. J Hazard Mater. 2002; 89:185-196. [PubMed: 11744204]

15. Viraraghavan T, Alfaro FDM. Adsorption of phenol from wastewater by peat, fly ash and bentonite. J Hazard Mater. 1998; 57:59-70.

16. Jiang H, Fang Y, Fu Y, Guo Q. Studies on the extraction of phenol in wastewater. J Hazard Mater. 2003; 101:179-190. [PubMed: 12927734] 
17. Liu F, Xia M, Yao S, Li A, Wu H, Chena J. Adsorption equilibria and kinetics for phenol and cresol onto polymeric adsorbents: Effects of adsorbents/adsorbates structure and interface. J Hazard Mater. 2008; 152:715-720. [PubMed: 17765398]

18. An F, Gao B, Feng X. Adsorption and recognizing ability of molecular imprinted polymer MIPPEI/SiO2 towards phenol. J Hazard Mater. 2008; 157:286-292. [PubMed: 18243547]

19. Senturka HB, Ozdesa D, Gundogdua A, Durana C, Soylakb M. Removal of phenol from aqueous solutions by adsorption onto organomodified Tirebolu bentonite: Equilibrium, kinetic and thermodynamic study. J Hazard Mater. 2009; 172:353-362. [PubMed: 19656623]

20. Abdelwahaba O, Amin NK, El-Ashtoukhy ESZ. Electrochemical removal of phenol from oil refinery wastewater. J Hazard Mater. 2009; 163:711-716. [PubMed: 18755537]

21. Lin SH, Pan CL, Leu HG. Liquid membrane extraction of 2-chlorophenol from aqueous solution. J Hazard Mater. 1999; 65:289-304.

22. Li K, Landriault M, Fingas M, Llompart M. Accelerated solvent extraction (ASE) of environmental organic compounds in soils using a modified supercritical fluid extractor. J Hazard Mater. 2003; 102:93-104. [PubMed: 12963285]

23. Welton T. Room-temperature ionic liquids. Solvents for synthesis and catalysis. Chem Rev. 1999; 99:2071-2083. [PubMed: 11849019]

24. Mochizuki Y, Sugawara K. Removal of organic sulfur from hydrocarbon resources using ionic liquids. Energy Fuels. 2008; 22:3303-3307.

25. Dietz ML, Stepinski DC. Anion concentration-dependent partitioning mechanism in the extraction of uranium into room-temperature ionic liquids. Talanta. 2008; 75:598-603. [PubMed: 18371927]

26. Fan J, Fan Y, Pei Y, Wu K, Wang J, Fan M. Solvent extraction of selected endocrine-disrupting phenols using ionic liquids. Sep Purif Technol. 2008; 61:324-331.

27. Meindersma GW, Podt A, Haan AB. Selection of ionic liquids for the extraction of aromatic hydrocarbons from aromatic/aliphatic mixtures. Fuel Process Technol. 2005; 87:59-70.

28. Nakashima K, Kubota F, Maruyama T, Goto M. Ionic liquids as a novel solvent for lanthanide extraction. Anal Sci. 2003; 19:1097-1098. [PubMed: 12945658]

29. Dai S, Ju YH, Barnes CE. Solvent extraction of strontium nitrate by a crown ether using roomtemperature ionic liquids. J Chem Soc, Dalton Trans. 1999:1201-1202.

30. Li M, Pittman CU Jr, Li T. Extraction of polyunsaturated fatty acid methyl esters by imidazoliumbased ionic liquids containing silver tetrafluoroborate - Extraction equilibrium studies. Talanta. 2009; 78:1364-1370. [PubMed: 19362202]

31. Hayashi S, Hamaguchi H. Discovery of a magnetic ionic liquid [bmim] $\mathrm{FeCl}_{4}$. Chem Lett. 2004; 33:1590-1591.

32. Li M, de Rooy SL, Bwambok DK, El-Zahab B, Ditusa JF, Warner IM. Magnetic chiral ionic liquids derived from amino acids. Chem Comm. 2009:6922-6924. [PubMed: 19904348]

33. Del Sesto RE, McCleskey TM, Burrell AK, Baker GA, Thompson JD, Scott BL, Wilkes JS, Williams P. Structure and magnetic behavior of transition metal based ionic liquids. Chem Commun. 2008:447-449.

34. Mallick B, Balke B, Felser C, Mudring AV. Dysprosium room-temperature ionic liquids with strong luminescence and response to magnetic fields. Angew Chem In Ed. 2008; 47:7635-7638.

35. Li M, Gardella J, Bwambok DK, El-Zahab B, de Rooy SL, Cole M, Lowry M, Warner IM. Combinatorial approach to enantiomeric discrimination: Synthesis and ${ }^{19}$ F NMR screening of a chiral ionic liquid-modified silane library. J Comb Chem. 2009; 11:1105-1114. [PubMed: 19824659]

36. Sakaebe H, Matsumoto H. N-Methyl-N-propylpiperidinium bis(trifluoromethane-sulfonyl)imide (PP13-TFSI) - novel electrolyte base for Li battery. Electrochem Comm. 2003; 5:594-598.

37. Fan Y, Chen M, Tu C, Zhu Y. A ionic liquid for dispersive liquid-liquid microextraction of phenols. J Anal Chem. 2009; 64:1017-1022.

38. Egorov VM, Smirnova SV, Pletnev IV. Highly efficient extraction of phenols and aromatic amines into novel ionic liquids incorporating quaternary ammonium cation. Sep Purif Technol. 2008; 63:710-715. 
39. Khachatryan KS, Smirnova SV, Torocheshnikova II, Shvedene NV, Formanovsky AA, Pletnev IV. Solvent extraction and extraction-voltammetric determination of phenols using room temperature ionic liquid. Anal Bioanal Chem. 2005; 381:464-470. [PubMed: 15578163]

40. Bekou E, Dionysiou DD, Qian R, Botsaris GD. Extraction of chlorophenols from water using room temperature ionic liquids. Ionic Liquids as Green Solvents: Progress and Prospects, ACS Symposium. 2003; 856:544-560. chapter 42.

41. Zhao F, Li J, Zeng B. Coupling of ionic liquid-based headspace single-drop microextraction with GC for sensitive detection of phenols. J Sep Sci. 2008; 31:3045-3049. [PubMed: 18704999]

42. Mohanty SM, Ranerjee T, Mohanty K. Quantum chemical based screening of ionic liquids for the extraction of phenol from aqueous solution. Ind Eng Chem Res. 2010; 49:2916-2925.

43. Le Z, Arlt W, Wasserscheid P. Separation of 1-hexene and n-hexane with ionic liquids. Fluid Phase Equilibria. 2006; 241:290-299.

44. McFerrin CA, Hall RW, Dellinger B. Ab Initio study of the formation and degradation reactions of chlorinated phenol. J Mole Structure: Theochem. 2009; 902:5-14.

45. Agency for Toxic Substances and Disease Registry (ATSDR). Toxicological Profile for Pentachlorophenol. Atlanta, GA: U.S. Department of Health and Human Services, Public Health Service; 2001. http://www.atsdr.cdc.gov/tfacts51.pdf 
Highlights

- Novel separation technique based on the use of magnetic extraction.

- Using a magnetic room temperature ionic liquid for removal of hazardous phenols from contaminated soil samples.

- Inherently safer and cleaner technique demonstrated highest extraction capacity as compared with previous regular non-magnetic RTILs.

- Successfully remove highly hazardous pentachlorophenol from superfund site contaminated soil samples with extremely high extraction capacity.

- Contributions of our work focus primarily on remediation of contaminated soil and groundwater. 


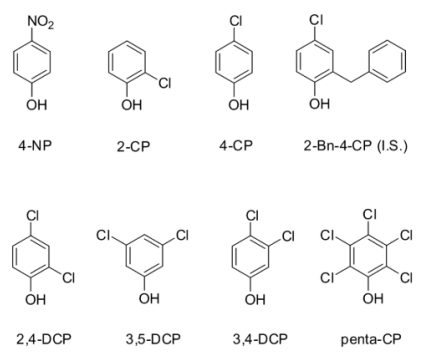

Fig. 1.

Structures of nitro- or chlorophenols 


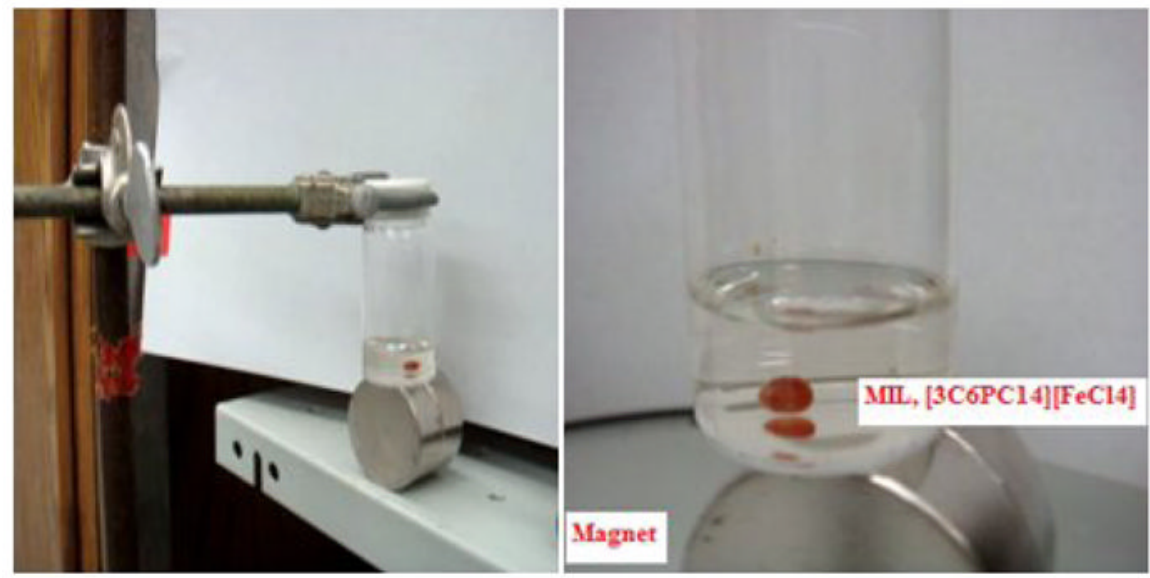

Fig. 2.

Experimental set-up of magnetic extraction 


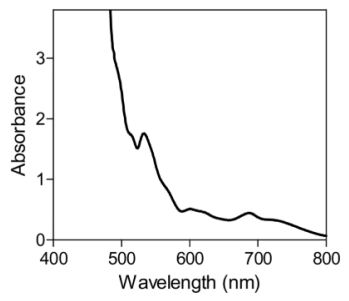

Fig. 3.

Visible absorption spectrum of $\left[3 \mathrm{C}_{6} \mathrm{PC}_{14}\right]\left[\mathrm{FeCl}_{4}\right]$ 
Sample: $\mathrm{PFeCl} 4$

Size: $3.3770 \mathrm{mg}$

Method: Ramp RT to 600

Comment: PFeCl4

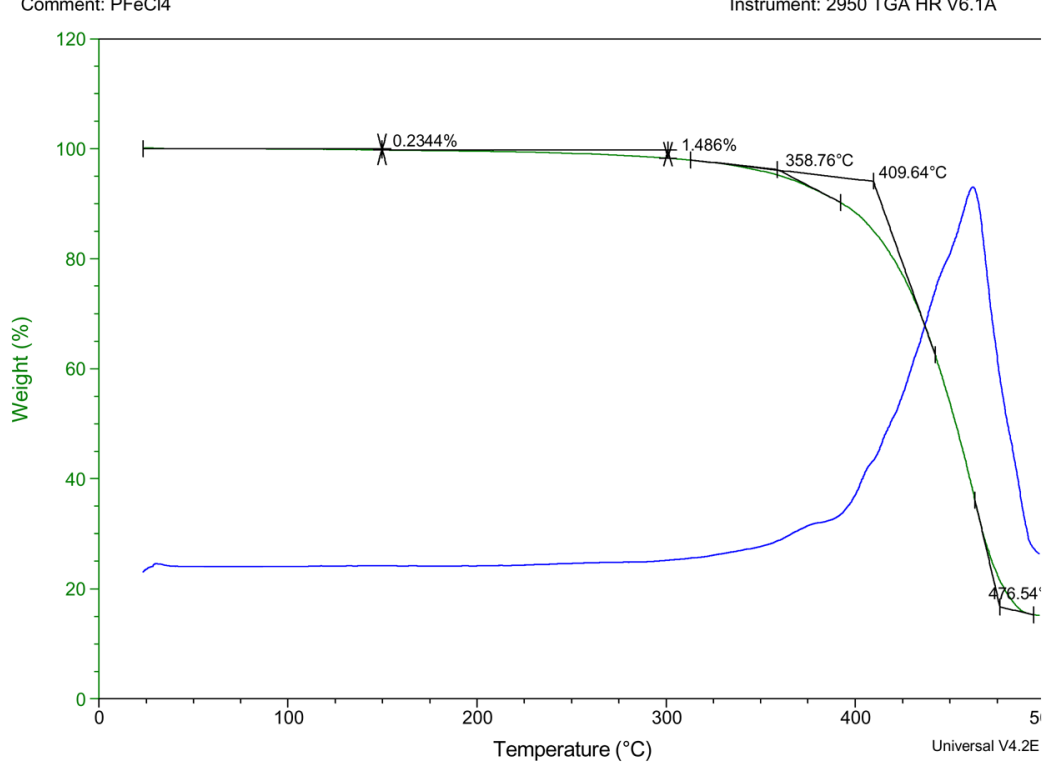

Fig. 4.

Thermal gravimetric analysis scan of $\left[3 \mathrm{C}_{6} \mathrm{PC}_{14}\right]\left[\mathrm{FeCl}_{4}\right.$ 


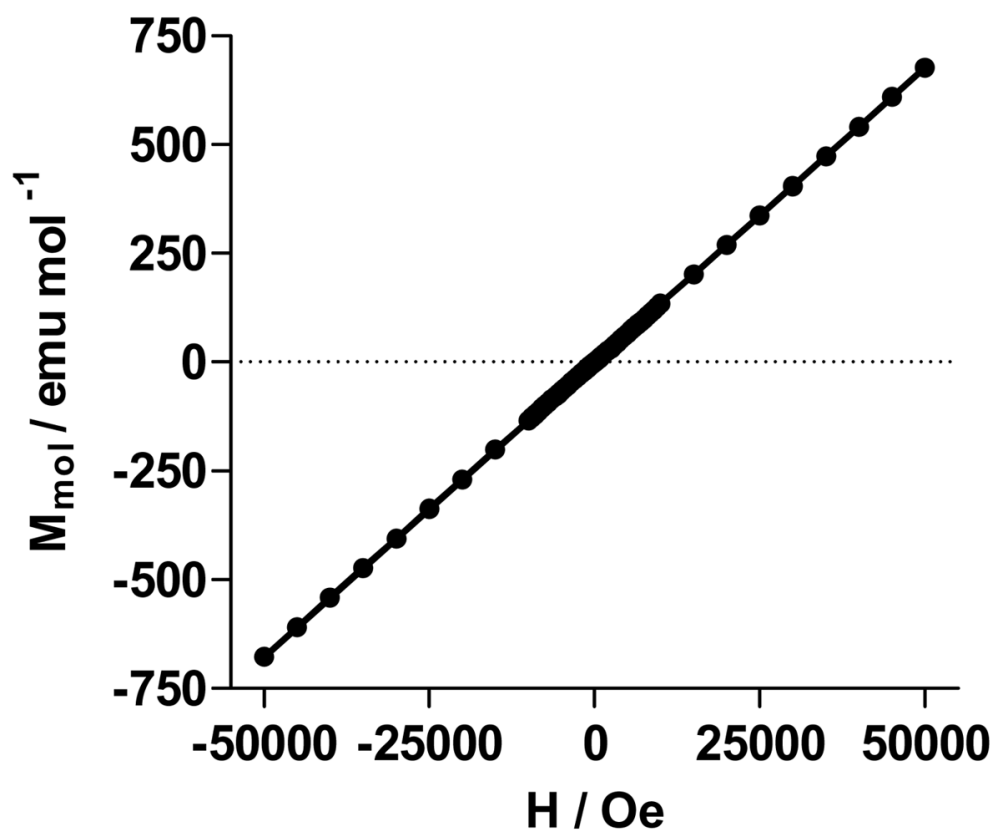

Fig. 5.

Field dependence of molar magnetization of $\left[3 \mathrm{C}_{6} \mathrm{PC}_{14}\right]\left[\mathrm{FeCl}_{4}\right]$ at $300 \mathrm{~K}$ 


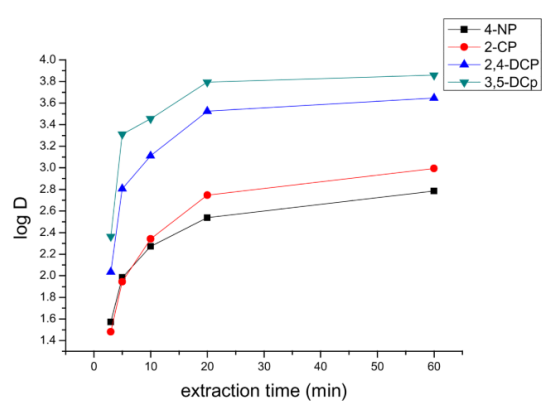

Fig. 6.

Effect of extraction time on distribution ratios of phenols 


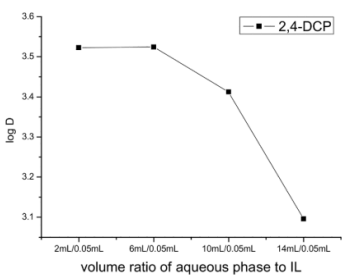

Fig. 7.

Effect of volume ratios between water and MRTIL on distribution ratios of phenols 


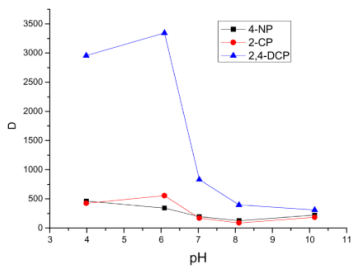

Fig. 8.

Effect of $\mathrm{pH}$ on distribution ratios of phenols 


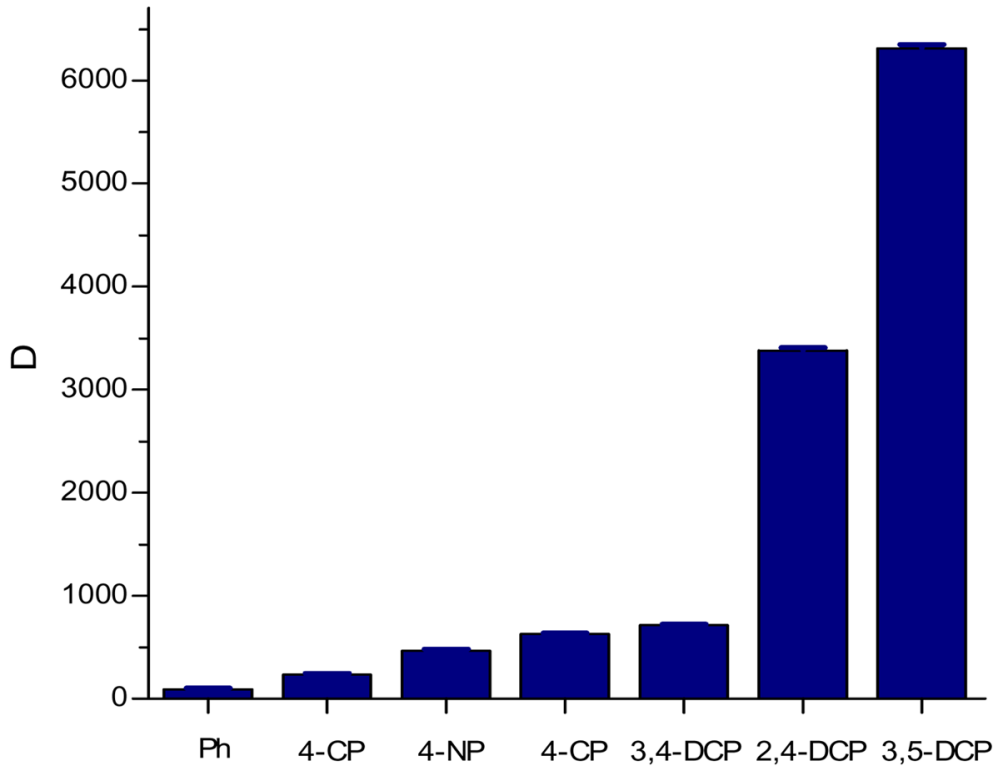

Fig. 9.

Distribution ratios of various phenols 


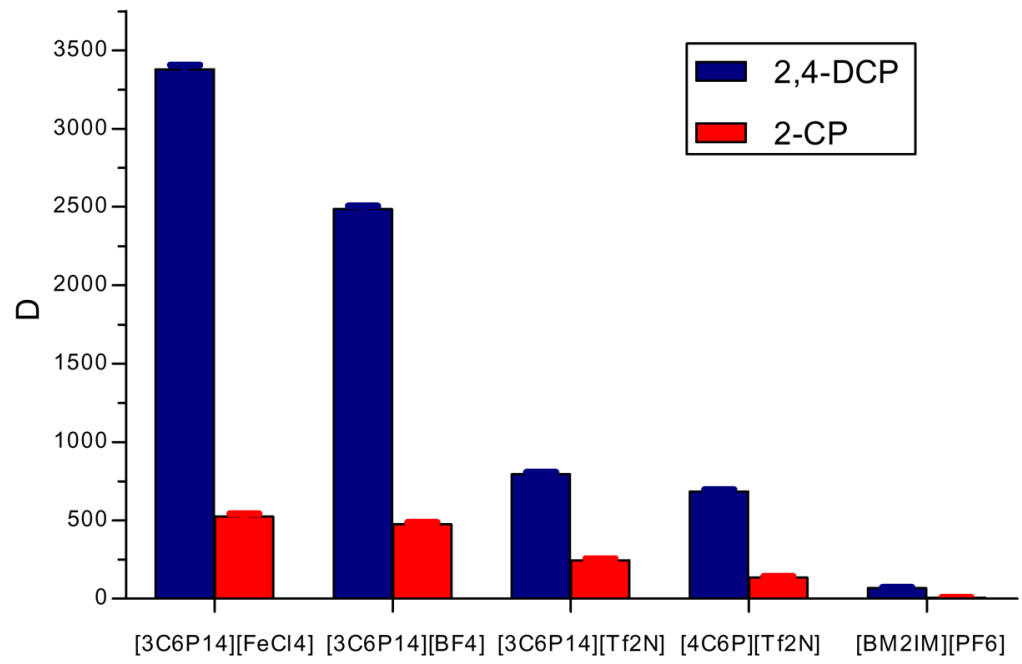

Fig. 10.

Distribution ratios of 2,4-DC and 2-CP in different ILs 


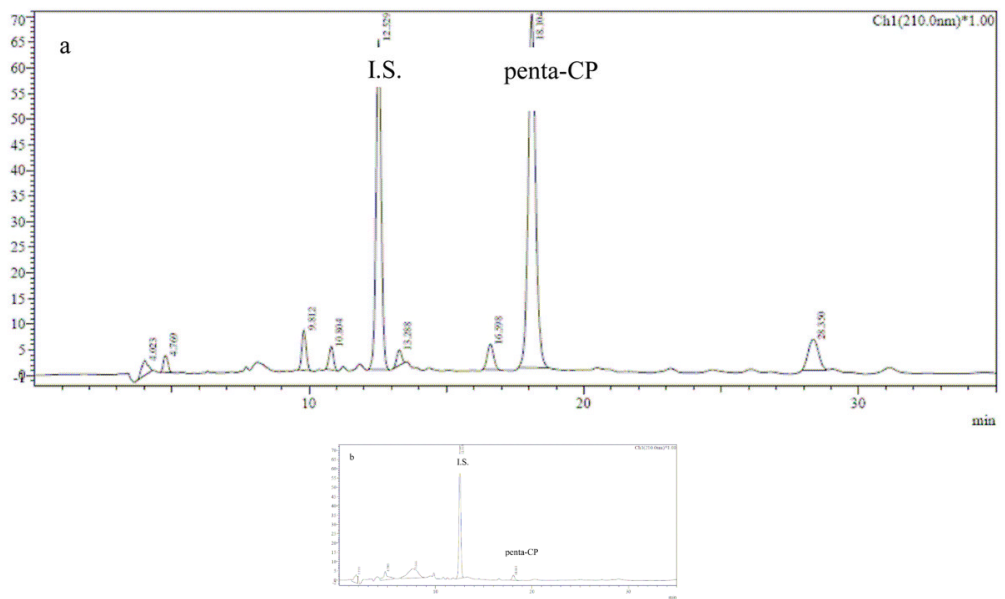

Fig. 11.

HPLC chromatograms of contaminated soil sample obtained from a superfund site, a) before extraction, b) after extraction by $\left[3 \mathrm{C}_{6} \mathrm{PC}_{14}\right]\left[\mathrm{FeCl}_{4}\right]$ 


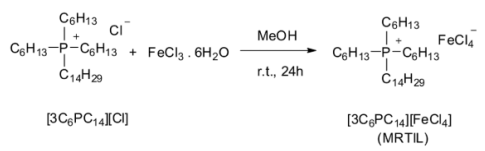

Scheme 1.

Synthesis of hydrophobic magnetic room temperature ionic liquid (MRTIL) 